\title{
PURIFICATION OF BILIRUBIN DIGLUCURONIDE AS AN ANALYTICAL STANDARD FRON PIG GALLBLADDER BILE AND ITS SOME PROPERTIES
}

Yukio MANABE

\author{
Department of the 2nd Clinical Laboratory, Tokyo Teishin
} Hospital, 14 - 23, 2-Chome, Fujimi, Chiyoda-ku, Tokyo, 102

Bilirubin diglucuronide was purified from pig gallbladder bile. All lipids except bile acids were removed by phase separation with acetone, petroleum ether and ammonium sulfate. Bile acids were removed using active charcoal and an anhydrous solvent. Bilirubin diglucuronide was extracted with pyridine from charcoal. Further purification was made using a Sephadex LH2O column and methanol as an eluent. Purities of the product averaged $90 \%$ and yields were about $6 \%$.

Conjugated bilirubin, especially diglucuronide, is often required for the biochemical studies of bilirubin and for the evaluation of the determination methods of bilirubin in serum. Methods of purification of conjugated bilirubin have been described in several reviews ${ }^{1) 2}$ )3). These methods often give poor yields and products of low purity. They are mostly caused by the insufficient removal of bile acids, especially glyco-conjugated bile acids. The present paper describes a purification procedure of bilirubin diglucuronide from pig gallbladder bile. The procedure consists of three major parts. (1) Separation of conjugated bilirubin together with bile acids from bile by phase separation. (2) Removal of bile acids from conjugated bilirubin using the difference of adsorption powers of the two components for active charcoal. (3) Purification of bilirubin diglucuronide by elution using a Sephadex LH2O column and methanol as an eluent.

\section{Materials and Methods}

Fresh pig gallbladder bile was added with mercaptoethanol to $l g / l$ as an antioxidant for bilirubin, and stored at $-20^{\circ} \mathrm{C}$. All solvents were dried with anhydrous sodium sulfate or by distillation, and added with mercaptoethanol. Active charcoal purchased from E. Merck, Darmstadt, Germany, Code No. 2186 was dried at $150^{\circ} \mathrm{C}$ for $3 \mathrm{~h}$. Plysurf A215C, Sephadex LH2O and hyodeoxycholic acid were purchased from Dai-ichi Kogyo Seiyaku Co., Kyoto, Pharmasia Fine Chemicals, Uppsala, Sweden and Calbiochem, San Diego, Calif., USA, respectively.

Purification procedure for bilirubin diglucuronide. 
Step 1 - Pig gallbladder bile $(50 \mathrm{ml})$ was mixed with acetone (150 $\mathrm{ml}$ ) and calcium carbonate powder $(0.5 \mathrm{~g})$, stirred and filtered. Step 2 - The filtrate was added with ammonium sulfate $(30 \mathrm{~g})$ and petroleum ether $(80 \mathrm{ml})$, shaken and allowed to stand for separation into 3 phases. Step 3 - The middle phase was washed with acetone (total volume about 150 - $200 \mathrm{ml}$ ) using a glass rod to insure complete pulverization, and then centrifuged. Step 4 - The precipitate was dried under reduced pressure, dissolved in a mixture of $2 \mathrm{~g}$ of phenol, $20 \mathrm{ml}$ of monochlorobenzene and $100 \mathrm{ml}$ of $\mathrm{n}$-butanol, and filtered by suction. Step 5 - Active charcoal (3 g) previously washed with the same solvent mixture was added to the filtrate, stirred and filtered by suction. Step 6 - Charcoal was washed with the solvent mixture (total volume about $200 \mathrm{ml}$ ) similarly, then conjugated bilirubin adsorbed was extracted with pyridine (total volume about 100 - $120 \mathrm{ml}$ ) from charcoal. Step 7 - Petroleum ether (1000 $\mathrm{ml}$ ) was added to the pyridine solution and stored for more than $15 \mathrm{~h}$ at $-20^{\circ} \mathrm{C}$. Conjugated bilirubin was precipitated at the bottom of the vessel. Step 8 - The precipitate was washed with petroleum ether, dissolved in methanol (6 ml) and added with $100 \mathrm{~g} / 1$ solution of Plysurf A215C in methanol ( $1 \mathrm{ml}$ ). Step 9 - The solution was applied to a Sephadex LH2O column (2 X $100 \mathrm{~cm}$, Sephadex LH2O was allowed to swell in methanol and packed), and eluted with methanol $(0.2 \mathrm{~g} / \mathrm{min})$. Four colored peaks were appeared. Step 10 - The 3rd peak fraction evaporated to dryness under reduced pressure was washed with petroleum ether (total volume about $100 \mathrm{ml}$ ) for removal of mercaptoethanol and a trace of Plysurf $\mathrm{A} 215 \mathrm{C}$, and thoroughly dried under reduced pressure.

Determination procedure for total bile acids.

The concentration of total bile acids in the product was determined by the method of $\mathrm{Abe}^{4)}$ with a modification as follows. Four ml of $1 \mathrm{~g} / \mathrm{l}$ vanillin in $85 \%$ phosphoric acid was added to $0.1 \mathrm{ml}$ of the sample solution, mixed and heated in a boiling water bath. After $10 \mathrm{~min}$ it was cooled in running water, added with $2 \mathrm{ml}$ of ethanol and mixed. The absorbance of the mixture was measured at $550 \mathrm{~nm}$ taking hyodeoxycholic acid as a standard.

Determination procedure for bilirubin and glucuronic acid moieties in a bilirubin diglucuronide fraction.

Bilirubin was determined by the method of Malloy and Evelyn ${ }^{5)}$. Glucuronic acid was determined by that of Fishman and Green ${ }^{6)}$.

Results and Discussion

The upper phase obtained by the procedure of Step 2 contained triglycerides, phospholipids, bile acids, bilirubin, ammonium sulfate, water and the organic solvents. The lower phase was a saturated solution of ammonium sulfate. At the bottom of the vessel, a small quantity of solid ammonium sulfate settled. The middle phase consisted mostly of bile acids and conjugated bilirubin.

The mixture of phenol, monochlorobenzene and n-butanol ( 1 : 10 : 50) was found to be the most suitable solvent for the separation of conjugated bilirubin on 
charcoal from bile acids regardless of their chemical structures and conjugation forms as shown in Table 1 .

Table 1. Adsorptivities of total bile acids and conjugated bilirubin to active charcoal (Step 5) in various solvents (\%).

\begin{tabular}{|c|c|c|}
\hline Solvent & Total bile acids & Conjugated bilirubin \\
\hline Acetic acid : acetone (15: 85$)$ & 10.5 & 78.5 \\
\hline Propionic acid : n-butanol ( 1 : 2) & 27.6 & 84.1 \\
\hline Propionic acid & 10.6 & 80.8 \\
\hline Phenol : n-butanol ( 1 : 10) & 1.4 & $73 \cdot 3$ \\
\hline$(1: 20)$ & 0.8 & 70.5 \\
\hline \multicolumn{3}{|l|}{ Phenol : monochlorobenzene : } \\
\hline n-butanol (1: $10: 20)$ & 0.1 & 68.9 \\
\hline$" \quad(1: 10: 50)$ & 0 & 67.3 \\
\hline
\end{tabular}

The determination was carried out using the filtrate obtained by the procedure of Step 5 .

Using the Sephadex LH2O column, 4 colored peaks were appeared. The lst peak contained urobilin (it showed an absorption maximum at $490 \mathrm{~nm}$, being shifted to $508 \mathrm{~nm}$ by adding zinc acetate, and showed green fluorescence). The 2nd peak contained biliverdin (it was estimated with its absorption spectrum). The 3 rd peak

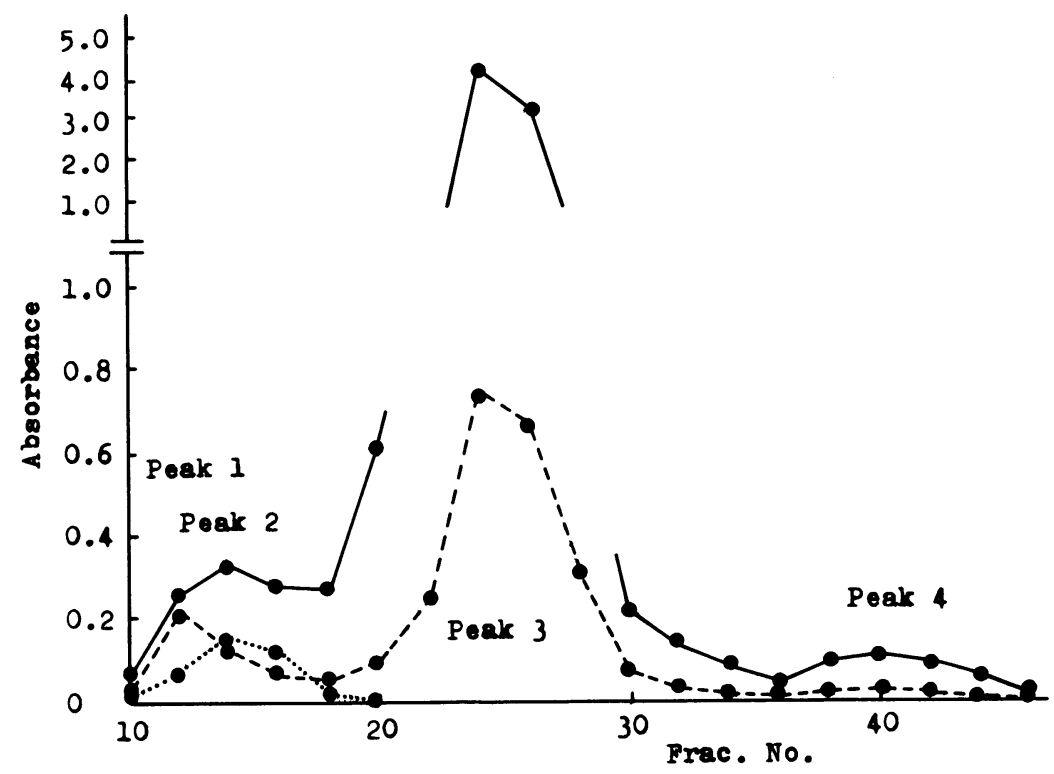

Fig. 1. Chromatogram obtained from Step 9 on a Sephadex LH2O column. Solid Iine : measured at $440 \mathrm{~nm}$; dashed line : $490 \mathrm{~nm}$; dotted line : $650 \mathrm{~nm}$. 
contained bilirubin diglucuronide and finally bilirubin monoglucuronide (molar ratios of bilirubin vs. glucuronic acid were 1 : 1.08 - 1.12) was eluted (Fig. 1). The color tone of each peak was dark brown, green, deep orange and pale yellow, respectively. The surfactant Plysurf $A 215 C$ was contained in the lst to 4 th peaks by the molar ratio of about $18: 82: 0.1: 0$.

The final product obtained by the purification procedure described above had the appearances of dark orange and amorphous powder. The product dissolved in phosphate buffer solution $(0.05 \mathrm{~mol} / \mathrm{l}, \mathrm{pH} 7.0)$ showed an absorption maximum at 440 $\mathrm{nm}$. The molar ratios of bilirubin vs. glucuronic acid were $1: 2.03-2.09$. The purities of the product were 88.6 - $91.1 \%(n=6)$. The yields from initial pig bile were $6.1-6.3$.

The indirect diazo reaction by the method of Malloy and Evelyn gave higher absorbance than that for the direct reaction as shown in Fig. 2.

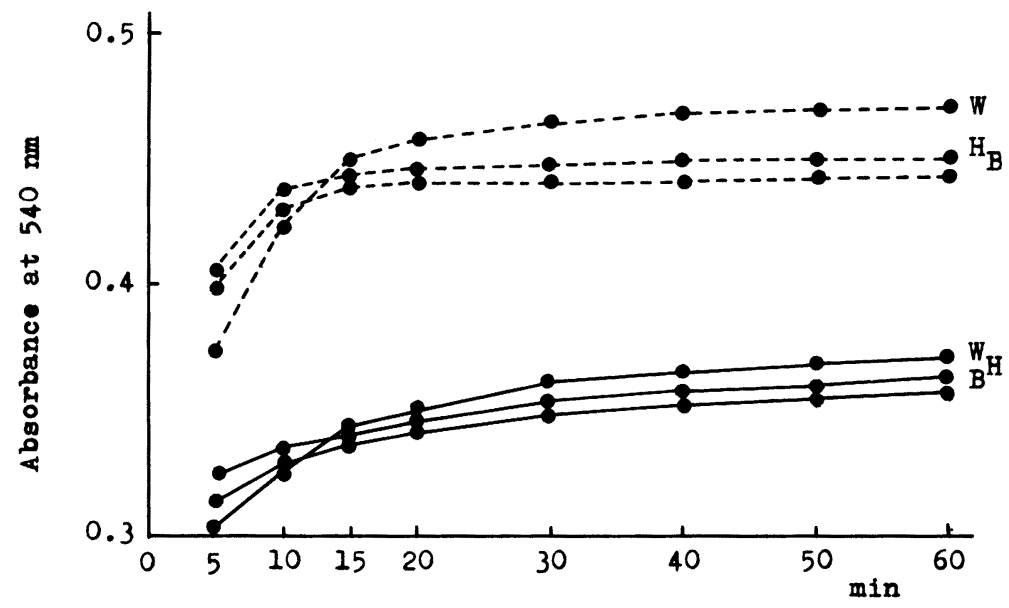

Fig. 2. Time courses of coupling reaction of bilirubin diglucuronide by the method of Malloy and Evelyn. Solid line : direct reaction; dashed line : indirect reaction. W : phosphate buffer solution $(0.05 \mathrm{~mol} / \mathrm{l}, \mathrm{pH} 7.0) ; \mathrm{H}: 50 \mathrm{~g} / \mathrm{l}$ human albumin in buffer solution; $B: 50 \mathrm{~g} / \mathrm{l}$ bovine albumin in buffer solution.

The product was stable at least for 6 months at $4^{\circ} \mathrm{C}$, when dissolved in the solvents and freeze-dried (Table 2).

The present method was applied to a human gallbladder bile obtained by the clinical autopsy, and bilirubin diglucuronide with similar purity was obtained.

The determination of bilimubin in serum using the product obtained by the method is under investigation, and will be described in the following paper. 
Table 2. Decreasing ratios (\%) of bilirubin diglucuronide during storage.

1) Stored at $-20^{\circ} \mathrm{C}$ (vacuum dried)

$\begin{array}{ccccccc}\text { Month } & 1 & 2 & 3 & 4 & 5 & 6 \\ & 0.7 & 0.8 & 1.4 & 1.8 & 2.1 & 2.5\end{array}$

2) Stored at $-20^{\circ} \mathrm{C}$ (dissolved in the solvents)

$\begin{array}{lllllll}\text { Week } & 2 & 4 & 6 & 8 & 10 & 12\end{array}$

Solvent

$\begin{array}{lllllll}\mathrm{H} & 0.4 & 0.4 & 0.4 & 2.5 & 1.5 & 4.1 \\ \mathrm{~B} & 2.1 & 1.2 & 2.1 & 2.7 & 3.7 & 4.9\end{array}$

3) Stored at $4^{\circ} \mathrm{C}$ (dissolved in the solvents and freeze-dried)

$\begin{array}{lllllll}\text { Month } & 1 & 2 & 3 & 4 & 5 & 6\end{array}$

Solvent

$\begin{array}{ccccccc}\mathrm{H} & 0 & 0 & 0.6 & 0.6 & 0.4 & 0.5 \\ \mathrm{~B} & 0.1 & 0.1 & 0.3 & 0.2 & 0.5 & 0.4\end{array}$

$\mathrm{H}: 50 \mathrm{~g} / \mathrm{l}$ humen albumin in buffer solution $(0.05 \mathrm{~mol} / \mathrm{l}, \mathrm{pH} 7.0): \mathrm{B}: 50 \mathrm{~g} / \mathrm{l}$ bovine albumin in buffer solution. Bilirubin diglucuronide was determined by the method of Malloy and Evelyn without accelerator.

Acknowledgement

The author is indebted to Professor Zenzo Tamura (Faculty of Pharmaceutical Sciences, University of Tokyo, Tokyo) for his valuable suggestions and encouragement during the course of this work.

\section{References}

1) E. Talafant, J. Appelt : Clin. Chem., 14, 208 (1968).

2) J. Jacobsen : Acta Chem. Scand., 23, 3023 (1969).

3) J. D. Ostrow, N. H. Murphy : Biochem. J., 120, 311 (1970).

4) Y. Abe : J. Biochem. (Tokyo), 25, 181 (1937).

5) H. T. Malloy, K. A. Evelyn : J. Biol. Chem., 119, 481 (1937).

6) W. H. Fishman, S. Green : ibid., 215, 527 (1955).

Keyword phrases

purification of bilirubin diglucuronide, pig gallbladder bile, active charcoal, Sephadex IH2O column. 